\title{
Children's Conceptions of Area Measurement and Their Strategies for Solving Area Measurement Problems
}

\author{
Hsin-Mei E. Huang ${ }^{1, *} \&$ Klaus G. Witz ${ }^{2}$ \\ ${ }^{1}$ Department of Learning and Materials Design, Taipei Municipal University of Education, Taipei 10048, Taiwan \\ ${ }^{2}$ Department of Curriculum and Instruction, University of Illinois at Urbana-Champaign, Champaign, IL 61820, \\ U.S.A \\ *Corresponding author: Department of Learning and Materials Design, Taipei Municipal University of Education, 1, \\ Ai-Guo W. Road, Taipei, 10048, Taiwan Tel: 886-2-2311-3040 \\ E-mail: hhuang22@tmue.edu.tw
}

Received: November 19, 2012

Accepted: December 11, 2012

Online Published: January 5, 2013

doi:10.5430/jct.v2n1p10

URL: http://dx.doi.org/10.5430/jct.v2n1p10

\begin{abstract}
This study investigated children's understanding of area measurement, including the concept of area and the area formula of a rectangle, as well as their strategic knowledge for solving area measurement problems. Twenty-two fourth-graders from three classes of a public elementary school in Taipei, Taiwan, participated in a one-on-one interview. Results show that the children who had a good understanding of the concept of area and the area formula (by using the property of multiplication) exhibited competency in identifying geometric shapes, using formulas for determining areas, and self-correcting mistakes. The children who had a good understanding of multiplication underlying the area formula, but misunderstood the concept of area, showed some ability to use area formulas. Conversely, the children who were unable to interpret the property of multiplication underlying the area formula irrespective of their conceptions of area exhibited the common weaknesses in identifying geometric shapes and differentiating between area and perimeter.
\end{abstract}

Keywords: area measurement; area formulas; problem solving

\section{Introduction}

Area measurement, which involves relating numerical quantity to a geometric attribute, is an important domain of school mathematics (Lehrer, 2003). Moreover, constructing and applying area formulas for measuring areas is an essential goal for learning area measurement for children in grades 4 to 6 (Council of Chief State School Officers [CCSSO], 2010; National Council of Teachers of Mathematics [NCTM], 2000; Taiwan Ministry of Education [TME], 2010). However, children's weaknesses in solving area measurement problems can be gleaned from data sets of national assessments (e.g., National Assessment of Educational Progress [NAEP] in the U. S.) and international assessments (e.g., The Trends in International Mathematics and Science Study [TIMSS]). For example, Lin and Tsai's (2003) analysis of TIMSS 2003 indicates that only 41.2\% of Taiwanese fourth-graders $(\mathrm{N}=1601)$ passed the area measurement problem (M011025). Such a poor performance also occurred among children from other countries, for example, the average of passing the problem (M011025) for fourth-graders from 23 participating countries was $29.4 \%$. Furthermore, an analysis of the 2011 NAEP-4M9 in the U. S. showed that only $24 \%$ of fourth-graders correctly found the area of a square given perimeter (National Center for Educational Statistics [NCES], 2011).

In the context of area measurement, two phenomena can be drawn often from fourth and fifth graders' performances of solving area measurement problems. First, they demonstrated good memorization of an area formula, but were less able to determine the areas of given configurations successfully (e.g., Bell, Costello, \& Küchemann 1983; Tan, 1998). Second, they have a preference for using the counting-and-addition strategy (Dickson, 1989). Given the evidence that children may show flexibility in using strategy for solving problems as described by Torbeyns, Verschaffel, and Ghesquiere (2004), it is argued that the use of the counting strategy, which demands more procedures, could easily lead to computation errors. Researchers suggest that it is a serious leap for children to move from using counting strategy to a conceptual understanding of a formula (Battista, 2003; Van de Walle, Karp, Bay-Williams, 2010). Hence, it is worthwhile investigating how different qualities of children's understanding of 
area measurement affect their strategies used for solving area measurement problem. Particularly, children who have been taught area measurement and area formulas.

Furthermore, shape identification, which represents geometric knowledge, lays the foundation for the development of area formulas of basic shapes (Owens \& Outhred, 2006). In particular, a good understanding of area formulas requires acquisition of the basic shapes and their properties, which in turn helps thinking about the logical relationships that exist between the formulas (Fuys, Geddes, \& Tischler, 1988; Owens \& Outhred, 2006). The ability to indentify the given shapes and to explain how to measure the areas of these shapes (e.g., how the area formulas can be applied by means of identifying given shapes) is a part of prominent knowledge for understanding area formulas. Hence, it is argued that children with different levels of understanding of area measurement may demonstrate different performance in the identification of geometric shapes.

This study aimed at gaining in-depth insight into fourth-grade children's understanding of area measurement, including the general concept of area and the area formula of a rectangle, as well as strategic knowledge in solving area measurement problems. The study examines the following questions:

1) How does the quality of children's understanding of area measurement affect their strategies for solving area measurement problems?

2) What is the relationship between the quality of children's understanding of area measurement and their performance with regard to shape identification?

\section{Theoretical background}

\subsection{Concepts involved in area and area measurement and the area formula of a rectangle}

The general concept of area refers to the amount of a 2-D region within a boundary, while area measurement concerns measuring the quantity of a surface enclosed within a 2-D region (Lehrer, 2003). Apparently, the latter knowledge is a more complicated subject-matter domain, one that incorporates the prior concept of area and measurement skills. Furthermore, determining area can be regarded as "a tiling of the plane with congruent regions that become units of measure" (Reynolds \& Wheatley, 1996, p. 567). The concepts of area measurement can be elaborated with three essential components: acquisition of shapes, measure, and computation of measure. Thus, the concept of area and the measurement of area should definitely be differentiated.

Dickson (1989) argued that due to insufficient preparation in the early stages of learning, children are prone to respond "multiplying length by width" to the word "area" while failing to consider the concept of shape. Since the differentiation of the concept of area from measuring area, which is a part of preliminary knowledge of area measurement taught for second-and third-grade students, fourth-grade children who have received more instruction and experience in measuring areas are assumed to be able to distinguish between the meanings of "area" and "measure area."

Understanding the area formula of a rectangle would require conceptualizing the row-by-column structure of a rectangular array, which is construction and coordination of a unit covered by a geometric shape, based on an understanding of the property of multiplication (Schifter \& Szymaszek, 2003). Through processes of covering up a rectangle with square units, children observe that "there are the same numbers of units in each row and in each column" and learn the additivity of area with the unions of grid squares. Furthermore, they should see the arrangement of columns and rows and meaningfully enumerate arrays of a square by using multiplication. As children develop more sophisticated procedures for the numeric calculation of grid squares, they can realize that the formula "Area = Length $\mathrm{x}$ Width $(\mathrm{A}=\mathrm{LxW})$ " for measuring rectangular figures is a faster alternative than employing the square counting method (Outhred \& Mitchelmore, 2000). Thus, it is argued that seeing the structure of rectangular arrays should be more sophisticated than seeing the repeated addition model and set model of multiplication (i.e., 2x3 can be modeled as two groups of 3) (Mulligan \& Mitchelmore, 1997).

\subsection{Children's strategy used for solving area measurement problems}

Using a numerical expression of area (e.g., area formula $\mathrm{A}=\mathrm{LxW}$ ) to represent the measurement of area and understanding why the particular formula works is a requisite skill involved in area measurement (TME, 2010). Furthermore, formulas assist us in using "easily made measures to determine indirectly some other measure that is not so easily found" (Van de Walle, 2004, p. 335). Although there are various ways to solve area measurement problems, appropriate use of formulas based on conceptual understanding can be considered an efficient strategy (Lehrer, Jaslow, \& Curtis, 2003). Comparatively, the use of counting-and-addition, which involves multiple 
procedures, is likely to result in computation errors (Dickson, 1989).

The previous studies (e.g., Outhred \& Mitchelmore, 2000; Reynolds \& Wheatley, 1996) indicated that fourth graders could understand the concept of rectangular arrays and those who adequately understand the row-by-column structure are competent in applying multiplicative strategy for determining the areas of rectangles. However, questions about whether children's execution of multiplicative calculations to determine the areas of rectangles represents a good understanding of area measurement and the formula $\mathrm{A}=\mathrm{LxW}$, and how such an understanding affects children's strategies used for measuring areas remain open.

In addition to acquisition of mathematical concepts, strategic knowledge, which is required to help children devise and monitor a solution, is vital for solving problems successfully (Mayer, 2008). The strategic knowledge of area measurement, which contains a conceptual understanding of area measurement, procedural fluency, and reflections on the accuracy of solutions for measuring areas, represents higher-order thinking skills (Lehrer, 2003). Alibali and Goldin-Meadow (1993) and Mayer (2008) also argued that children who have strategic knowledge of a class of problems are able to indicate their problem-solving strategies, including problem-solving processes and whether the solution plan needs to be modified.

Furthermore, Barrett and Clements (2003) and Malloy (1999) argued that a better concept of area and perimeter grounded on acquisition of geometric concepts. Thus, it is argued that children's application of area formulas and their performance in identifying geometric shapes and in modifying their erroneous solutions of area measurement are related to the quality of understanding of area measurement.

\section{Method}

This study extends the literature on children's understanding of area and area formula of a rectangle. This study reports the interview data which were mentioned informally in the quantitative study in Huang and Witz (2011).

Briefly, in Huang and Witz (2011), there were three fourth-grade classes in a public elementary school in Taipei, Taiwan, were recruited to undergo instructional treatments of area measurement. Each class was randomly assigned to receive one of the three treatments concerning area measurement (AM), geometry motions (GM), and both geometry motions and area measurement (GMAM). The treatments, which took four class-periods to implement, aimed to guide the children in exploring the area formulas of parallelograms and triangles by using decomposition and recomposition and the concept of the formula $\mathrm{A}=\mathrm{LxW}$. Upon completion of the treatments, all the children were asked to complete a paper-and-pencil post-test on area measurement. One-on-one interviews, which took about two consecutive days to complete, were conducted on the day following the post-test.

The interview data analyzed in the present study focused on emergent categories in children's understanding of area measurement and in their strategies. (The informal remarks in Huang and Witz (2011) focused on children's learning gains from instruction.)

\subsection{Participants}

Twenty-two fourth-graders (14 boys and 8 girls) participated in the interview, including 20 interviewees who were randomly selected in each treatment group and two interviewees who volunteered to participate in the interview and who did not pass the screen-test in Huang and Witz (2011). Their mean age was 10 years $(M=120.00$ months, $S D=$ 3.30). Moreover, all of the participants had possessed the knowledge of unit covering and iterations in area measurement.

\subsection{Design of study and structure of interview}

One-on-one, task-based interviews were employed to access children's understanding of the concepts of area measurement, based on Goldin's (2000) suggestions. All interviews were audio-taped. The interview consisted of three parts, including different questions and figures (see Appendix B). Part I aimed at gauging children's conception of area by questioning the participants about the meaning of area.

Part II probed the children's understanding of the formula A=LxW. Participants were provided with a $3 \times 2$ rectangular array and $1 \mathrm{~cm}^{3}$ blocks, which were common manipulatives used in mathematics class, to facilitate their explanation.

Part III explored children's mathematical thinking and their strategies for solving the three area measurement problems for which area formulas could be simply applied for solving problems (see Appendix A). The rationale for selecting the problems included two considerations. First, the three problems which consisted of three types of problems with reference to the revealed problems of the NAEP (National Assessment Governing Board, 2005) 
yielded an effective way to obtain children's understanding of area measurement and problem-solving strategies. They were numerical area calculation problems [i.e., the area-of-the-triangle problem with grids (Q1a), the area-of-the-triangle problem without grids (Q2), and the area-of-the-parallelogram problem with grids (Q3)] and mathematical judgment problems [i.e., the item which demanded mathematical judgments about the perimeter and area formulas of a rectangle (Q1b)] and explanation problems [i.e., the reasons explained for making the judgment of Q1b]. Second, children's understanding of area measurement and area formulas could be assessed from children's verbal explanations for explaining the solutions they used to solve problems through interviews, coupled with their written solutions, as shown on the paper-and-pencil posttest.

The interviewees were shown their answer sheets in the paper-and-pencil test and were asked how they solved each of the area measurement problems and how they came up with such an approach. If a participant had difficulty in explaining his/her ideas in response to Part III problems, a short description of the problems or a brief instruction would be given. An example of the brief instruction given to the participants on solving Q2 of Part III is illustrated in Appendix C.

Furthermore, when the participants responded to the problems in Part III, the codes "positive" or "negative" were used to indicate whether or not the names of shapes for explaining thinking of measuring the areas of the given shapes were clearly indicated (on their own initiative). If, on their own initiative, a participant pointed out the names of shapes (i.e., without any prompts given from the interviewer) that represented a child's competency with identification and naming of shapes and vice verse. Contrarily, the participants who received a brief instruction were coded "negative" because they did not identify the geometric shapes using their own initiative.

\subsection{Data analysis and coding scheme}

Two sets of data were analyzed. One focused on the children's written solutions to the three problems; Q1a, Q2, and Q3. The other focused on the children's verbal responses to the interview questions about their understanding of area measurement and mathematical thinking when solving the three given problems, including Q1b.

All interviews were transcribed and the interviewees' solutions written on the post-test were coded separately. The coding scheme adopted for each aforementioned analysis is described as follows.

\subsubsection{Children's conceptions of area (Part I)}

Children's conceptions of area were classified into two categories according to their responses. (a) "Conceptual interpretation": Children who could explain that area means "the size of a shape surface" or "the amount of surface" were classified into this category. (b) "Procedural interpretation and misconception": Children who believed that multiplying length by width represents the meaning of area do not differentiate the general concept of area from the meaning of measuring area (Dickson, 1989). Thus, children who asserted that area means "length times width" and those who indicated incorrect conceptions of area were classified into this category.

\subsubsection{Children's understanding of the area formula of a rectangle (Part II)}

There were two categories classified, based on the children's explanations for the meaning of the area formula of a rectangle, interpretation of "multiplication" and "non-multiplication." a. "Multiplication." This category included two subcategories according to which model of multiplication that children interpreted. (i) "Array-based approach." Children who indicated "2 rows of 3 and 3 columns of 2" or "it is a 2-by-3 array and a 3-by-2 array also" were classified into this category. (ii) "Set model of multiplication." Children who were categorized as "set model of multiplication" could point out "2 groups of 3" or "3 groups of 2". b. "Non-Multiplication". Children who could explain neither the meaning of the formula $\mathrm{A}=\mathrm{LxW}$ nor the property of multiplication embedded in the rectangular arrays were classified into this category.

\subsubsection{Classification of children's strategies for area measurement (Part III)}

The strategies used by the children were classified into three categories according to their written solutions, namely, "Use-of-the-standard-formulae," "Multiple-step," and "Inaccurate." All of these children's strategies were primarily categorized based on the written arithmetical equations and procedures rather than their verbal explanations and the computation results.

Children categorized as "Use-of-the-standard-formulae" were those who applied appropriately the formulas "Area = (Base $x$ Height $) / 2$ " $(\mathrm{A}=\mathrm{BxH} / 2)$ and "Area = Base $\mathrm{x}$ Height" $(\mathrm{A}=\mathrm{BxH})$ for determining the area of a triangle and a parallelogram, respectively.

Those using 'Multiple-step' strategies took more steps to calculate the area. For example, as can be seen in Figure 1, multiple procedures were used for determining the area of the given parallelogram though the result of computation 
was incorrect. This case was also categorized to "Multiple-step." Other examples of "Multiple-step" strategies include counting or re-arranging parts of a parallelogram to form a rectangle coupled with using the formula $\mathrm{A}=\mathrm{LxW}$, as well as square counting, all of which involve multiple procedures.

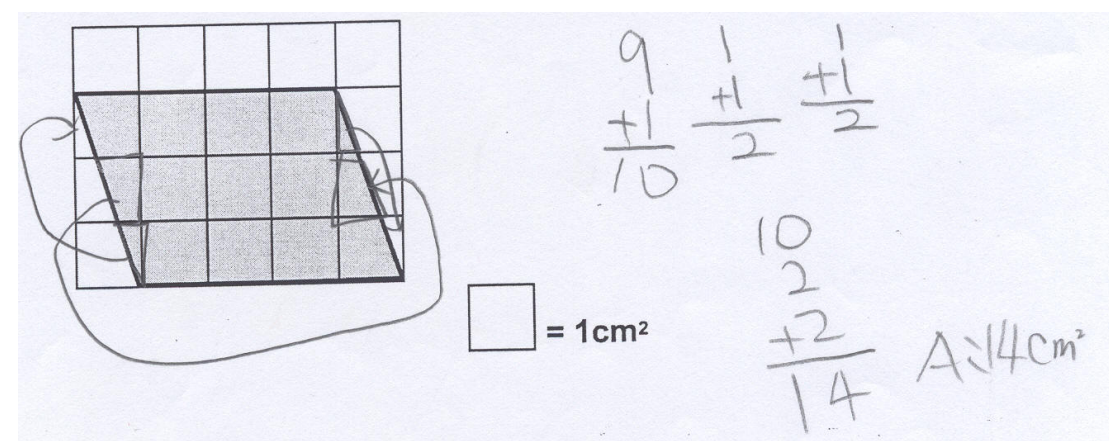

Figure 1: An example of "multiple-step" strategy used for determining the area of the parallelogram

Additionally, participants with 'inaccurate' strategies used incorrect or inappropriate procedures, leading to failure in solving the problems.

\subsubsection{Classification of understanding of area measurement}

To gauge the relationship between the quality of children's understanding of area measurement and their strategies for determining areas, the quality of understanding was classified into different groups based on the children's understanding of Area and their interpretations of the area Formula (A=LxW) assessed. In this study, "A" and "F" denoted understanding of Area and the Formula, respectively. " $a$ " and " $f$ " denoted a lack of understanding of Area and the Formula, respectively.

Consequently, there were four categories for grouping children's understanding of area measurement, namely AF, $a \mathrm{~F}$, $\mathrm{A} f$, and $a f$. (a) AF. Children classified as AF were those who not only had a correct conception of area, but were also able to interpret the formula by using an array-based approach or a set model of multiplication. (b) $a \mathrm{~F}$. Children classified as $a \mathrm{~F}$ were those who could only explain the formula by using multiplication but at the same time they had inaccurate conceptions of area. (c) A $f$. Children classified as A $f$ were those who only had a correct conception of area, but were unable to interpret the property of multiplication embedded in the formula. (d) af. Children classified as af were those who had inaccurate conceptions of area; nor could they interpret the multiplication embedded in the formula.

\section{Results}

\subsection{Coding reliability of children's interview responses and their strategies}

All transcripts and interview data were examined and coded by two independent raters according to the categories and coding schemes described above. For children's "conception of area," the results of Kappa analyses were at .93, $p<.001$. Moreover, consensus was reached by the two raters on all disagreements. For assessing inter-rater reliability for the coding of categories of children's interpretation of the formula $\mathrm{A}=\mathrm{LxW}$ and strategies, the results of Kappa analyses were at .89, $p<.001$ and $.79, p<.001$, respectively. Additionally, the inter-rater agreement for the coding of children's initiative in describing the names of geometric shapes reached $100 \%$.

\subsection{Children's understanding of area measurement}

\subsubsection{Children's conceptions of the concept of area}

Thirteen of the 22 children (13/22) were able to express a conceptual interpretation for the concept of area. For example, one of the children identified in the category, "conceptual interpretation," indicated "area means the amount of a plane figure," and another child expressed "Area is about ... a plain figure. Then, when you want to calculate its size, you need to use that "length times width'."

Conversely, nine of the 22 children (9/22) who indicated the area concept with the means of calculating it or had misconceptions of area were identified as "Procedural interpretation and misconception." This included five children 
who mixed up the concept of area with measuring area (5/9); two children who believed that multiplying length by width represents area and perimeter (2/9); and two children who regarded "area" as an object (2/9). Among the two children who regarded "area" as an object, one child indicated,

"area is ..., is the size of the location of an object, the size of the location."

while the other child expressed,

"A square. A square is area."

Table 1 lists the frequency of the categories of children's conceptions of area and their interpretation of the area formula of a rectangle.

Table 1: Frequency of children's conception of area by their interpretation of the meaning of area formula of a rectangle

\begin{tabular}{|c|c|c|c|c|c|c|}
\hline & \multicolumn{4}{|c|}{ Conception of Area } & \multirow{2}{*}{\multicolumn{2}{|c|}{ Total }} \\
\hline & \multicolumn{2}{|c|}{$\begin{array}{l}\text { Conceptual } \\
\text { interpretation }\end{array}$} & \multicolumn{2}{|c|}{$\begin{array}{l}\text { Procedural } \\
\text { interpretation and } \\
\text { misconception }\end{array}$} & & \\
\hline & $\mathrm{n}$ & $\%$ & $\mathrm{n}$ & $\%$ & $\mathrm{n}$ & $\%$ \\
\hline \multicolumn{7}{|l|}{ Interpretation of the formula } \\
\hline \multicolumn{7}{|l|}{ 1. Multiplication } \\
\hline a. Array-based approach & 1 & $4 \%$ & - & - & 1 & $4 \%$ \\
\hline b. Set model of multiplication & 10 & $45 \%$ & 6 & $27 \%$ & 16 & $73 \%$ \\
\hline \multicolumn{7}{|l|}{ 2. Non-multiplication } \\
\hline a. Rote-memorization of the formula & 1 & $4 \%$ & 2 & $9 \%$ & 3 & $14 \%$ \\
\hline b. Counting and misconceptions & 1 & $4 \%$ & 1 & $4 \%$ & 2 & $9 \%$ \\
\hline Total & 13 & $59 \%$ & 9 & $41 \%$ & 22 & $100 \%$ \\
\hline
\end{tabular}

\subsubsection{Children's interpretation of the area formula of a rectangle}

As Table 1 shows, 17 of 22 children (17/22) were identified as interpretation of "multiplication," including one child who used the array-based approach and 16 children who used the "set model of multiplication." The child who adopted an array-based approach stated,

"There were 2 rows with 3 squares in each (or 3 columns with 2 squares in each). If this side is the 'length' (i.e., the horizontal side of the $2 \times 3$ rectangle) and the other side is the 'width' (i.e., the vertical side of the $2 \times 3$ rectangle that is perpendicular to the length side), then the area of the rectangle is $2+2+2=6$ or $3+3=6$. Thus, we can use multiplication to calculate the area. So, the area is $2 \times 3=6\left(\mathrm{~cm}^{2}\right)$. It is the formula 'length times width'."

The remaining 16 children (16/17) described the number of girds shown on the rectangle by using the set model of multiplication, for example, "If there are 2 groups of tiles and each group consists of 3 tiles, then the total is 6 tiles." Nevertheless, they did not explain the structure of rectangular arrays on the basis of coordinating two dimensions of units.

Five of the 22 children (5/22) who could not explain the meaning of the formula using the property of multiplication were identified as "non-multiplication." Among the five children who were classified as "non-multiplication," three children indicated directly "length times width" along with pointing out the sides of the rectangle, and two children whose approach involved counting the grids given on the rectangle without any explanation.

\subsubsection{The quality of children's understanding of area measurement}

Children's responses could be categorized into the four groups which represent different quality of understanding of area measurement. The number of children categorized into the AF, $a \mathrm{~F}, \mathrm{~A} f$, and $a f$ groups were $11(11 / 22)$, six (6/22), two $(2 / 22)$, and three $(3 / 22)$, respectively. All of the $\mathrm{A} f$ and $a f$ children could not explain why the procedure of multiplying works for determining the area of a rectangle though they memorized the concept that the area of a rectangle could be determined by calculating the tiles covering the rectangle or by "length times width." 
4.3 Relationship between quality of children's understanding of area measurement and strategies for determining areas

4.3.1 Children's strategies for area measurement

Table 2 displays the frequency of the four groups with different quality of understanding and strategies for determining areas. As shown in Table 2, seven (to 10) of the 11 children who successfully solved the three respective problems were in the AF group, with most of them identified as formula-users. Moreover, when a grid is not provided with the figures given, 10 of the 11 AF children (10/11) were formula-users, whereas only one of the six $a \mathrm{~F}$ children (1/6) was a formula-user. Conversely, none of the children in the A $f$ or $a f$ groups used formulas to solve the problems.

Table 2: Frequency of different quality of understanding of area measurement and strategies used for determining the areas of triangles and parallelograms

\begin{tabular}{|c|c|c|c|c|c|c|c|c|c|}
\hline \multirow[t]{2}{*}{ Question and Strategy } & \multicolumn{2}{|c|}{$\mathrm{AF}$} & \multicolumn{2}{|c|}{$a \mathrm{~F}$} & \multicolumn{2}{|c|}{ Af } & \multicolumn{2}{|c|}{ af } & \multirow[t]{2}{*}{ Total } \\
\hline & $f$ & $\%$ & $f$ & $\%$ & $f$ & $\%$ & $f$ & $\%$ & \\
\hline \multicolumn{10}{|c|}{ Q1a. Determine the area of a triangle with a grid given } \\
\hline a. Using formula $A=(B \times H) / 2$ & 10 & $91 \%$ & 1 & $17 \%$ & - & - & - & - & 11 \\
\hline \multicolumn{10}{|l|}{ b. Using multiple-step strategies } \\
\hline i. Counting & - & - & 1 & $17 \%$ & 2 & $100 \%$ & - & - & 3 \\
\hline ii. Using formula $\mathrm{A}=\mathrm{L} \times \mathrm{W}$ and counting & - & - & 2 & $33 \%$ & - & - & - & - & 2 \\
\hline c. Using inaccurate strategies & 1 & $9 \%$ & 2 & $33 \%$ & - & - & 3 & $100 \%$ & 6 \\
\hline Total & 11 & $100 \%$ & 6 & $100 \%$ & 2 & $100 \%$ & 3 & $100 \%$ & 22 \\
\hline \multicolumn{10}{|c|}{ Q2. Determine the area of a triangle with no grid given } \\
\hline a. Using formula $A=(B \times H) / 2$ & 10 & $91 \%$ & 1 & $17 \%$ & - & - & - & - & 11 \\
\hline b. Using inaccurate strategies & 1 & $9 \%$ & 5 & $83 \%$ & 2 & $100 \%$ & 3 & $100 \%$ & 11 \\
\hline Total & 11 & $100 \%$ & 6 & $100 \%$ & 2 & $100 \%$ & 3 & $100 \%$ & 22 \\
\hline \multicolumn{10}{|c|}{ Q3. Determine the area of a parallelogram with a grid provided } \\
\hline a. Using formula $\mathrm{A}=\mathrm{B} \times \mathrm{H}$ & 7 & $64 \%$ & 1 & $17 \%$ & - & - & - & - & 8 \\
\hline \multicolumn{10}{|l|}{ b. Using multiple-step strategies } \\
\hline i. Counting & - & - & 3 & $50 \%$ & 1 & $50 \%$ & 3 & $100 \%$ & 7 \\
\hline ii. Using formula $\mathrm{A}=\mathrm{L} \times \mathrm{W}$ and counting & 2 & $18 \%$ & - & - & - & - & - & - & 2 \\
\hline c. Using inaccurate strategies & 2 & $18 \%$ & 2 & $33 \%$ & 1 & $50 \%$ & - & - & 5 \\
\hline Total & 11 & $100 \%$ & 6 & $100 \%$ & 2 & $100 \%$ & 3 & $100 \%$ & 22 \\
\hline
\end{tabular}

Moreover, the formula users who were from the AF group were more likely to show consistency in using area formulas for determining the areas of different figures, whereas the Af and $a f$ children were less likely to use area formulas. Looking closely at the $a \mathrm{~F}$ group, there were only three children that were identified as formula-users. Furthermore, each of the three formula-users who were in the $a \mathrm{~F}$ group merely applied a specific area formula for solving one of the three problems given on the test.

4.3.2 The relationship between the quality of children's understanding of area measurement and their strategies

To examine the relationship between the quality of children's understanding of area measurement and their strategies for determining areas, Chi-square analyses were performed.

The results of Chi-square analyses for solving Q1a was $\chi^{2}(6, N=22)=25.69, p<.001$, and for solving $\mathrm{Q} 2$ was $\chi^{2}(3$, $N=22)=15.03, p<.01$. Not surprisingly, the AF group had a higher percentage of formula-users than the other three groups.

A close look at the children's inaccurate strategies for solving Q2, the approach of 'adding up the lengths of sides of provided with the figures given' was found to be frequently adopted by the A $f$ and $a f$ groups. In addition, this 
approach, directly applying the area formula of a rectangle, could be found frequently adopted in the $a \mathrm{~F}$ group.

For area measurement of a parallelogram (Q3), the results showed that the association between the quality of children's understanding and their application of the area formula of a parallelogram did not reach significance, $\chi^{2}(6$, $N=22)=10.55, p=.10$.

4.4 Children's strategic knowledge of area measurement and their initiative in indicating the names of geometric shapes

The interview data regarding the children's explanations of their mathematical thinking when solving area measurement problems revealed distinctive characteristics between the four groups with different quality of understanding of area measurement. Table 3 summarizes the characteristics of children's different levels of understanding and their strategic knowledge in solving area measurement problems. The marked differences existing among the four groups are described below.

Table 3: Summary of children's performance in solving area measurement problems according to their quality of understanding of area measurement

\begin{tabular}{llll}
\hline Performance & Good understanding & Partial understanding & Poor understanding \\
\hline 1. Group & AF group & $a$ F and Af groups & af group
\end{tabular}

2. Conception of the Accurate conception general idea of area

3. Ability to explain the meaning of the area formula of a rectangle

\section{Ability to distinguish between measuring perimeter and measuring an area}

\section{Strategies for measuring areas}

\begin{abstract}
Able to use array-based approach or set model of multiplication to explain the formula
\end{abstract}

Able to distinguish the two measures

a. Most children were formula-users

b. Used formulas and less efficient strategies; c. Less likely to use inaccurate strategies whenever the given figures were provided with or without grids a. $a \mathrm{~F}$ children had an inaccurate conception of area b. A $f$ children had a procedural interpretation or confusion with area and measuring area

a. $a \mathrm{~F}$ children were able to use set model of multiplication to explain the formula b. A $f$ children had a rote memorization of the formula or counting grids without explanations for the formula

Less able to distinguish between these two measures

Mixed up the two measures
a. A $f$ and $a$ F groups tended to use multiple-step strategies, and inaccurate strategies, though few of children in the $a \mathrm{~F}$ group showed some ability to use formulas.
b. Both $\mathrm{A} f$ and $a \mathrm{~F}$ children were likely to use inaccurate strategies a. Used multiple-step strategies and inaccurate strategies; b. Likely to use incorrect strategies whenever the given figures were provided with or without grids when grids were not provided with the figures given 


\begin{tabular}{|c|c|c|c|}
\hline $\begin{array}{l}\text { 6. Children's } \\
\text { initiative of } \\
\text { describing the } \\
\text { names of } \\
\text { geometric } \\
\text { shapes }\end{array}$ & $\begin{array}{l}9 \text { out of the } 11 \\
\text { children, on their own } \\
\text { initiative, described the } \\
\text { names of geometric } \\
\text { shapes }\end{array}$ & $\begin{array}{l}\text { a. } 4 \text { out of the } 6 a \mathrm{~F} \text { children, on } \\
\text { their own initiative, described the } \\
\text { names of geometric shapes } \\
\text { b. None of the } 2 \mathrm{~A} f \text { children, on } \\
\text { their own initiative, described the } \\
\text { names of geometric shapes }\end{array}$ & $\begin{array}{l}1 \text { out of the } 3 \text { children, } \\
\text { on their own initiative, } \\
\text { described the names of } \\
\text { geometric shapes }\end{array}$ \\
\hline $\begin{array}{l}\text { 7. Strategic } \\
\text { knowledge } \\
\text { (Identification } \\
\text { and } \\
\text { self-correction } \\
\text { of erroneous } \\
\text { solutions) }\end{array}$ & $\begin{array}{l}\text { Able to identify and } \\
\text { self-correct erroneous } \\
\text { solutions without any } \\
\text { need of brief } \\
\text { instruction }\end{array}$ & $\begin{array}{l}\text { a. } a \text { F children were able to } \\
\text { identify and self-correct } \\
\text { erroneous solutions after being } \\
\text { provided brief instruction } \\
\text { b. A } f \text { children were less able to } \\
\text { identify and self-correct } \\
\text { erroneous solutions even after } \\
\text { being provided brief instruction }\end{array}$ & $\begin{array}{l}\text { a. Less able to identify } \\
\text { and self-correct } \\
\text { erroneous solutions even } \\
\text { after being provided } \\
\text { brief instruction }\end{array}$ \\
\hline
\end{tabular}

When computing the area of a figure without a provided grid, the AF children were inclined to spontaneously produce images of a rectangle and a rectangular array. They frequently pointed out, "You can imagine having grids on the figure even though a grid is not provided." They tended to explain how the figures can be cut up and rearranged into a configuration to which previously learned formulas can be applied. An example can be seen in the written explanations and solution displayed in Figure 2. The solution shown in Figure 2 illustrates that "8x2=16, $16 \div 2=8$. Two triangles can form a rectangle. Firstly, I determine the area of the rectangle and calculate the area, and then divide it by 2." Even though they gave incorrect solutions on the test, they could identify their errors and promptly indicate how to correct them.

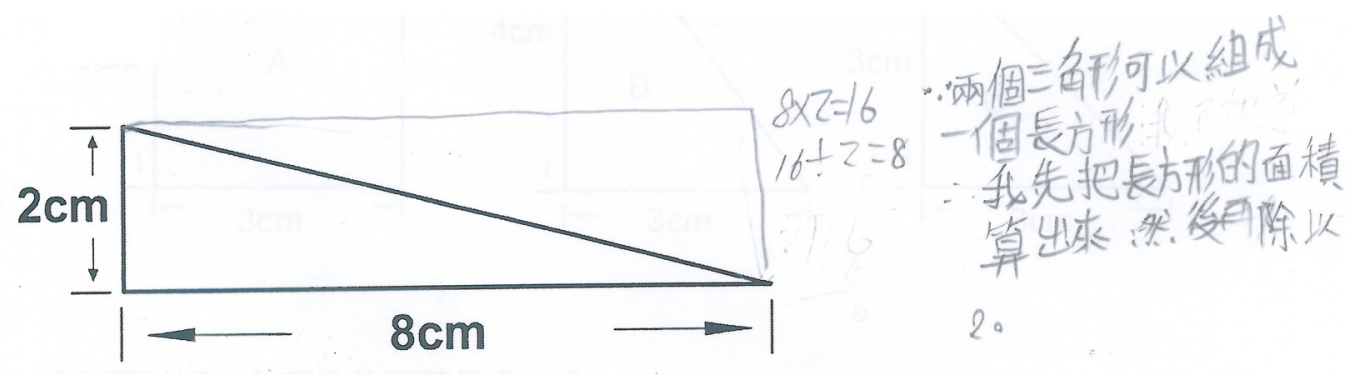

Figure 2: An example of a formula-user's explanation regarding the inferrance and calculations for determining the area-of-the-triangle

In contrast, children who were in the other three groups needed the assistance of a brief instruction which explained strategies they could use for solving the area measurement problems. Aided by this instruction, the $a$ F children could point out the mistakes they made on the posttest and proceed to self-correct their errors.

Finally, the $\mathrm{A} f$ and $a f$ children could provide numerical answers or short answers, but were less able to explain their strategies or how their procedures worked to produce the answer at which they arrived. Moreover, they were less able to identify and self-correct their errors.

As to children's initiative toward indicating the names of the geometric shapes, nine of the $11 \mathrm{AF}$ children (9/11) and four of the six $a$ F children (4/6) explicitly indicated the names of the shapes when they explained the procedures of measuring areas, whereas only one of the three children who were in the af group (1/3) did so. None of the A $f$ children indicated the names of the shapes on their own initiative.

Additionally, for justifying the solution statement regarding measuring the area of the given triangle $(\mathrm{Q} 1 \mathrm{~b}), 10$ of the 11 AF children (10/11) could make justification and clearly point out the difference between perimeter and measuring the area of a triangle given, while only two of the six $a \mathrm{~F}$ children (2/6) did so. The remaining four $a \mathrm{~F}$ children and all of the $\mathrm{A} f$ and $a f$ children could not make justification on Q1b. Furthermore, with provided grids, they tended to create and arrange $1 \mathrm{~cm}^{2}$ square units for area calculation, and the multiple procedures involved made their 
strategies tedious and less efficient. Without provided grids, they frequently used inaccurate strategies, which led to erroneous solutions.

\section{Discussion}

In this study, the interview data showed that all the fourth-graders interviewed displayed good memorization skills regarding the area formula of a rectangle. Nevertheless, approximately two-fifths of the children were found to have difficulty in differentiating the general concept of area from measuring area. Some of them (5/22) could not explain the property of multiplication underlying the formula $\mathrm{A}=\mathrm{LxW}$. While the quality of their understanding varied, children with a good understanding exhibited competency in using area formulas, identifying the geometric shapes, self-correcting the erroneous solutions, and ability to justify the solution statement regarding measuring perimeter and areas. Contrarily, these characteristics were less likely to be observed in the groups with partial or poor understanding such as the $\mathrm{A} f, a \mathrm{~F}$, and $a f$ groups.

Based on the above findings, several instructional implications can be drawn for improving children's understanding of area measurement and the effectiveness of their strategies for solving area measurement problems.

\subsection{Children's understanding of area measurement}

These findings suggest that fourth-grade children who have some experience in measuring areas and good memorization of the formula do not necessarily have an accurate conception of area. Such an observation implies that children's concrete experience of tiling and their acquisition of area formulas were not well connected.

Although prior research has suggested that fourth-graders can understand the property of multiplication underlying the area formula of a rectangle (e.g., Outhred \& Mitchelmore, 2000), findings from this study showed that most of the children's explanations focused on the set model of multiplication. Seeing the connection of area measurement of a rectangle to the array-based model of multiplication demands identifying a shape's spatial components and integrating components into a row-by-column composite (Schifter \& Szymaszek, 2003). Thus, this acquisition is more sophisticated than the memorization of multiplication and then seeing the set model of multiplication (Lin, Tasi, \& Yang, 2009). These results exhibit that the structure of rectangular arrays may still pose difficulty for some fourth-graders who have received instruction of area measurement (e.g., the Af and af children). Children's insufficiency in understanding of the formula $\mathrm{A}=\mathrm{LxW}$, which cannot easily be assessed from either students' memorization of the area formulas or numerical calculations by means of paper-and-pencil tests. It implies that a thorough scrutiny of students' conception of multiplication and their knowledge of 2-D geometry and area-- which may help instructors obtain more information about students' latent deficiencies in area measurement should be considered.

Moreover, since mastering multiplication facts and numerical calculations of area does not represent an understanding of the structure of rectangular arrays, instructors should go beyond numerical calculations and memorization of area formulas for strengthening students' conceptual understanding of area formulas. A thorough scrutiny of students' conception of multiplication and their knowledge of 2-D geometry and area measurement--which may help instructors obtain more information in terms of students' latent deficiencies in area measurement--should be considered as an essential part of instruction.

Meanwhile, school mathematics and instruction has a significant impact on students' learning of mathematics (Ball \& Rowan 2004), the issues regarding the nature of the cultural perspectives on school mathematics and instruction pervasive in the elementary schools in Taiwan may help explain some of the results regarding the fourth-graders' tendency to use the set model of multiplication to interpret the meaning of the formula $\mathrm{A}=\mathrm{LxW}$. First, compared with the set model of multiplication problems demonstrated in the textbooks series (from first-grade to fourth-grade) used in elementary schools in Taiwan, the quantity of the array-based multiplication problems appears much less than that of set model multiplication problems. Moreover, most Taiwanese teachers' mathematics teaching tended to follow the content of the textbooks (Askew, Hodgen, Lossain, \& Bretscher, 2010, p. 34). Under this circumstance, when array-based multiplication problems were displayed less frequently in the textbooks, students may have less experience in handling the array model of multiplication. Second, elementary school teachers in Taiwan tended to explain the property of multiplication by using the set model when introducing the rectangular arrays based on interview data of inservice elementary school teachers (paper in preparation). Perhaps this lack of experience in handling array-based multiplication problems, coupled with the set model of multiplication introduced for the area formula of a rectangle received from instruction led to these results. The issue regarding how the content of mathematics textbooks and instruction influences on children's interpretation of area formulas needs further 
investigations.

5.2 Relationship between quality of children's understanding of area measurement and strategies for area measurement

The findings evidence the significant impact of quality of children's understanding of area measurement on their strategies used for solving area measurement problems and on explaining their thinking of measuring areas. Although use of inaccurate approach happened among the groups, children with good understanding showed competence in self-correcting mistakes, whereas children with incomplete understanding needed an instructional assistance for correcting mistakes. These findings echo Rabinowitz, Freeman, and Cohen's (1992) perspective that effective strategy use involves more than solely about the strategy; it also involves having knowledge of when and why a strategy can be used, plus the ability to execute the perceived strategy.

In this study, children with good understanding of area and the area formula (e.g., the AF group) seemed better able to indicate the shapes and how the various formulas work for determining the areas of given figures than those children with incomplete understanding (e.g., the $\mathrm{A} f, a \mathrm{~F}$, and $a f$ groups). These findings support the perspective that the greater the body of geometric knowledge children can access, the more effective their performance when using that knowledge (Chinnappan, 1998).

Considering the current findings, to what extend do children's knowledge of area and their understanding of the area model of multiplication impact on solving area measurement problems? The discussion includes three aspects. First, in this study, none of the $\mathrm{A} f$ and a $f$ children were formula-users. They displayed the common characteristic, a lack of understanding of the formula $\mathrm{A}=\mathrm{LxW}$ and inability to apply standard area formulas for determining areas. Moreover, compared with the $\mathrm{A} f$ children, two to three $a \mathrm{~F}$ children displayed some ability to use area formulas for determining areas. Although the $\mathrm{A} f$ children acquired the concept of area, this acquisition only seems to be insufficient for effectively using area formulas. Thus, children's inadequacy in understanding of the area model of multiplication may potentially impair their application of area formulas for solving problems. Second, compared with the AF children, the $a \mathrm{~F}$ children did not display a stable ability to apply the area formulas for determining areas. Also, their strategic knowledge of area measurement such as using formulas and justifying perimeter and measuring areas did not seem as stable as the AF children. It suggests that the need for providing instruction clarifying the concepts of area and measuring areas and area model of multiplication to children who have this incomplete understanding.

Furthermore, these findings regarding $\mathrm{A} f$ and a $f$ children's tendency to use counting for determining areas may echo Siegler and Stern's (1998) suggestions that children are prone to using a shortcut strategy as long as they have sufficient knowledge of the strategy and experience in using it to successfully solve problems. Only when children have insufficient knowledge of the shortcut strategy or when they find it more difficult to solve a problem, do they tend to adopt backup strategies, such as counting and addition. Although a sign of flexibility can be seen in the children's use of strategies for solving area measurement problems, being able to perform counting-and-addition does not represent a full understanding of the concepts of area measurement or the multiplication property underlying the structure of rectangular arrays. As suggested by Reynolds and Wheatley (1996), the counting strategy seems to be an alterative for fourth graders when measuring areas, especially to those children who have an inadequate understanding of the structure of rectangular arrays.

In a sense, instructors should note that even with full illustration of the complete tiling process, some children may still fail to grasp the concept of area and the structure of arrays within a rectangular region, and that knowing when to apply multiplication does not mean that a complete understanding of the area formula of a rectangle has been achieved. Moreover, instructors must give careful attention to the non-formula-users' understanding of multiplication concepts, unit concepts for spatial measurement, and knowledge of 2-D geometry (e.g., Barrett, Cullen, Sarama, Clements, Klanderman, Miller, \& Rumsey, 2011). When children have acquired the concept of the structure of rectangular arrays, instructors may remove the grids from the given figures to stimulate children to adopt other strategies instead of the counting-and-addition approach.

\subsection{Suggestions for future research and limitation}

On the basis of the children's strategies used in solving area measurement problems, it is clear that children with a better understanding of area measurement will have greater success in applying formulas to area measurement problems and will provide clearer explanations of their approaches, in addition to modifying their erroneous solutions. This is especially true in the application of the formula " $\mathrm{A}=\mathrm{BxH} / 2$ " to determine the area of a triangle, when no grid has been provided.

As to the limitation of the current study, findings of this study were obtained from a small sample of fourth graders' 
solutions to area measurement problems. The descriptions of children's conceptions of area measurement discussed in this study might be viewed as researchable presumptions. These presumptions merit further studies with larger samples and more area measurement problems to investigate the effectiveness of the instructional suggestions.

Moreover, the study centered on children's use of the area formulas when solving the area measurement problems on paper-and-pencil assessments. Future research needs to focus on children who have partial or poor understanding while exploring their mathematical thinking about multiplication, as well as their difficulty in connecting the concept of 2-D geometry with area measurement. Whether poor application of the area formulas results from an insufficient acquisition of 2-D geometry, such as geometric shapes and their properties, also merits further investigations.

\section{References}

Alibali, M. W., \& Goldin-Meadow, S. (1993). Gesture-speech mismatch and mechanisms of learning: What the hands reveal about a child's state of mind. Cognitive Psychology, 25(4), 468-523. http://dx.doi.org/10.1006/cogp.1993.1012

Askew, M, Hodgen, J., Lossain, S., \& Bretscher, N. (2010). Values and variables. Mathematics education in high-performing countries. London, Great British: Nuffield Foundation. http://dx.doi.org/10.1109/TAC.1960.1105020

Ball, D. L., \& Rowan, B. (2004). Introduction: Measuring instruction. The Elementary School Journal, 105(1), 3-10. http://dx.doi.org/10.1086/428762

Barrett, J. E., \& Clements, D. H. (2003). Quantifying path length: Fourth-grade children's developing abstractions for linear measurement. Cognition and Instruction, 21(4), 475-520. http://dx.doi.org/10.1207/s1532690xci2104_4

Barrett, J. E., Cullen, C., Sarama, J., Clements, D. H., Klanderman, D., Miller, A. L., \& Rumsey, C. (2011). Children's unit concepts in measurement: a teaching experience spanning grade 2 through 5. ZDM Mathematics Education, 43, 637-650. http://dx.doi.org/10.1007/s11858-011-0368-8

Battista, M. T. (2003). Understanding students' thinking about area and volume measurement. In D. H. Clements \& G. Bright (Ed.), Learning and teaching measurement: 2003 year book (pp. 122-142). Reston, VA: National Council of Teachers of Mathematics.

Bell, A. W., Costello, J., \& Küchemann, D. (1983). A review of research in mathematical education. (Part A: Research on learning and teaching). England, Windsor: NFER-Nelson Publishing Company.

Chinnappan, M. (1998). Schemas and mental models in geometry problem solving. Educational Studies in Mathematics, 36(3), 201-217. http://dx.doi.org/10.1023/A:1003134323371

Council of Chief State School Officers. (2010). Common core state standards. Retrieved from http://www.corestandards.org/the-standards

Dickson, L. (1989). Area of a rectangle. In K. Hart, D. C. Johnson, M. Brown, L. Dickson, \& R. Clarkson (Eds.). Children's mathematical frameworks 8-13: A study of classroom teaching (pp.89-125). England, Windsor: NFER-Nelson Publishing Company.

Fuys, D., Geddes, D., \& Tischler, R. (1988). The van Hiele model of thinking in geometry among adolescents. Journal for Research in Mathematics Education, Monograph, 3, 1-195. http://dx.doi.org/10.2307/749957

Goldin, G. A. (2000). A scientific perspective on structured, task-based interview in mathematics education research. In A. E. Kelly, \& R. A. Lesh (Eds.), Handbook of research design in mathematics and science education (pp. 517- 545). Mahwah, NJ: Lawrence.

Huang, H.-M. E. (2009). An experiment of two-dimensional spatial geometry and area measurement concepts integrated curriculum and instruction. (In Chinese) Chinese Journal of Science Education, 17(6), 509-530.

Huang, H.-M. E., \& K. G. Witz (2011). Developing children's conceptual understanding of area measurement: A curriculum and teaching experiment. Learning and Instruction, 21, 1-13. http://dx.doi.org/10.1016/j.learninstruc.2009.09.002

Lehrer, R. (2003). Developing understanding of measurement. In J. Kilpatrick, W. G. Martin, \& D. Schifter (Eds.), $A$ research companion to Principles and Standards for School Mathematics (pp. 179-192). Reston, VA: National Council of Teachers of Mathematics.

Lehrer, R., Jaslow, L., \& Curtis, C. L. (2003). Developing an understanding of measurement in the elementary grades. 
In D. H. Clements \& G. Bright (Eds.), Learning and teaching measurement (pp. 100-121). Reston, VA: National Council of Teachers of Mathematics.

Lin, P.-J., \& Tsai, W.-H. (2003). Fourth graders' achievement of mathematics in TIMSS 2003 field test. (In Chinese) Science Education Monthly, 258, 2-20.

Lin, P.-J., Tasi, B.-Q., \& Yang, I.-I. (2009). Alternative materials and methods for teaching whole number multiplication: Theory and practice. (In Chinese) Taipei, Taiwan: Shi-Ta Bookstore.

Malloy, C. E. (1999). Perimeter and area through the van Hiele model. Mathematics Teaching in the Middle School, 5, 87-90.

Mayer, R. E. (2008). Learning and instruction ( $2^{\text {nd }}$ ed.). Upper Saddle River, NJ: Pearson Education.

Mulligan, J. T., \& Mitchelmore, M. C. (1997). Young children's intuitive model of multiplication and division. Journal for Research in Mathematical Education, 28 (3), 309-330. http://dx.doi.org/10.2307/749783

National Assessment Governing Board (2005). Mathematics framework for the 2005 National Assessment of Educational Progress. Washington, DC: The Author. Retrieved from http://nces.ed.gov/pubsearch/pubsinfo.asp?pubid=1999074

National Center for Educational Statistics (2011). NAEP Questions. Retrieved from National Center of Educational Statistics Web site: http://nces.ed.gov/nationsreportcard/itmrls/

National Council of Teachers of Mathematics (2000). Principles and standards for school mathematics. Reston, VA: The author.

Outhred, L. N., \& Mitchelmore, M. C. (2000). Young children's intuitive understanding of rectangle area measurement. Journal for Research in Mathematics Education, 31, 144-167. http://dx.doi.org/10.2307/749749

Owens, K., \& Outhred, L. (2006). The complexity of learning geometry and measurement. In A. Gutiérrez \& P. Boero (Eds.), Handbook of research on the psychology of mathematics education: Past, present and feature (pp. 83-115). Rotterdam, The Netherlands: Sense Publishers.

Rabinowitz, M., Freeman, K., \& Cohen, S. (1992). Use and maintenance of strategies: The influence of accessibility to knowledge. Journal of Educational Psychology, 84(2), 211-218. http://dx.doi.org/10.1037/0022-0663.84.2.211

Reynolds, A., \& Wheatley, G. H. (1996). Elementary students' construction and coordination of units in an area setting. Journal for Research in Mathematics Education, 27, 564-581. http://dx.doi.org/10.2307/749848

Schifter, D., \& Szymaszek, J. (2003). Structuring a rectangle: Teachers write to learn about their students' thinking. In D. H. Clements \& G. Bright (Eds.), Learning and teaching measurement. 2003 year book (pp. 143-156). Reston, VA: National Council of Teachers of Mathematics.

Siegler, R. S., \& E. Stern, E. (1998). Conscious and unconscious strategy discoveries: A microgenetic analysis. Journal of Experimental Psychology: General, 127(4), 377-397. http://dx.doi.org/10.1037/0096-3445.127.4.377

Taiwan Ministry of Education (2010). Grade 1-9 Curriculum for Junior High School and Elementary School: Mathematics $\left(3^{\text {rd }}\right.$ ed.). Taipei, Taiwan: The Author.

Tan, N. J. (1998). A study on the students' misconceptions of area in the elementary school. (In Chinese) Journal of National Taipei Teachers College, XI, 573-602.

Torbeyns, J., Verschaffel, L., \& Ghesquiere, P. (2004). Strategic aspects of simple addition and subtraction: The influence of mathematical ability. Learning and Instruction, 14, 177-195. http://dx.doi.org/10.1016/j.learninstruc.2004.01.003

Van de Walle, J. A. (2004). Elementary and middle school mathematics: Teaching developmentally. (5 ${ }^{\text {th }}$ ed.). New York: Pearson Education.

Van de Walle, J. A., Karp, K. S., \& Bay-Williams, J. M. (2010). Elementary and middle school mathematics: Teaching developmentally ( $8^{\text {th }}$ ed.). Upper Saddle River, NJ: Pearson Education. 


\section{APPENDIX A}

\section{Test of area measurement}

1. a. What is the area of the shaded triangle? How did you figure out the answer? You may use equations to explain your ideas.
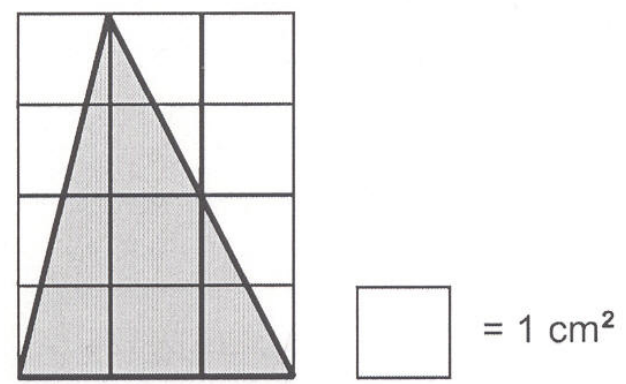

b. Tim says, "The area of the triangle is $3+4+3+4=14,14 \div 2=7\left(\mathrm{~cm}^{2}\right)$ ". Do you agree with his idea? Why or why not?

2. What is the area of the triangle? How did you figure out the answer? You may use equations to explain your ideas.

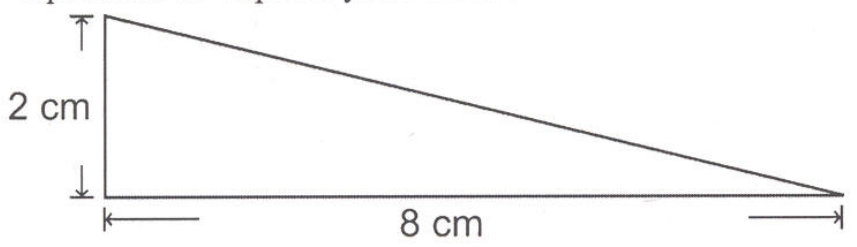

3. What is the area of the shaded parallelogram?

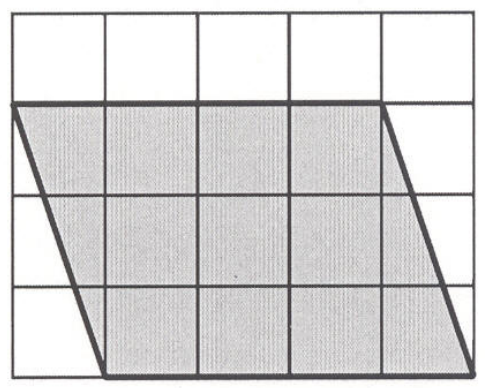

$=1 \mathrm{~cm}^{2}$ 


\section{APPENDIX B}

Interview Questions

$\underline{\text { Part I }}$

(a) "Would you tell me what the meaning of 'area' is?"

\section{Part II}

"Would you tell me the meaning of the area formula 'Area $=$ Length $\times$ Width' by using the $3 \times 2$ rectangular array? You may use the $1-\mathrm{cm}^{3}$ blocks to explain your ideas." Figure 1 illustrates the $3 \times 2$ rectangular array shown to the interviewees.

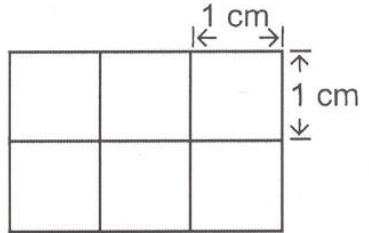

Figure 1. $3 \times 2$ rectangular array. 


\section{$\underline{\text { Part III }}$}

Q1a. "What is the area of the shaded triangle? How did you figure out the answer?

You may use equations to illustrate your ideas."

"Would you tell me how you solve the problem?"
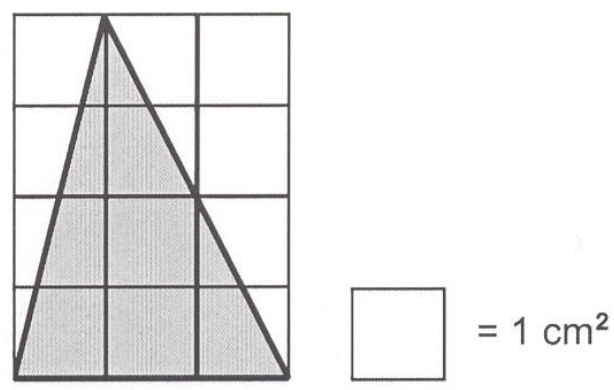

Q1b. "Tim says, 'The area of the triangle is $3+4+3+4=14,14 \div 2=7\left(\mathrm{~cm}^{2}\right)$ '. Do you agree with his idea? Why or why not?"

"Would you tell me how you solve the problem?"

Q2. "What is the area of the triangle? How did you figure out the answer? You may use equations to illustrate your ideas."

"Would you tell me how you solve the problem?"

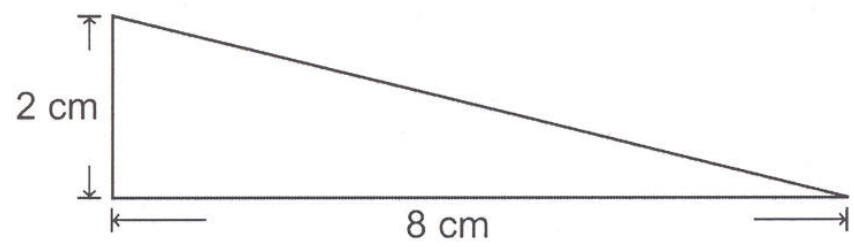

Q3. "What is the area of the shaded parallelogram?"

"Would you tell me how you solve the problem?"

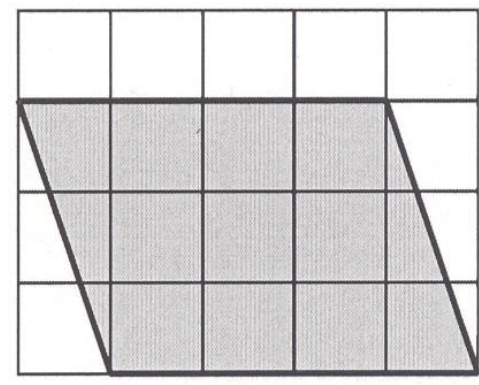

$=1 \mathrm{~cm}^{2}$ 


\section{APPENDIX C}

Example of the Brief Instruction Provided by the Interviewer for Measuring the Area of the Triangle with No Grids Given

Interviewer: Would you tell me how you solve the problem? [Point to the triangle of Q2 shown in the test.]

Interviewee: ... [Thinking but no response.]

Interviewer: OK. Look, let's use the $1-\mathrm{cm}^{2}$ square units on the $1-\mathrm{cm}^{3}$ blocks to tile the triangle. [Take the blocks to cover up the height, $2 \mathrm{~cm}$, of the triangle.] See, these blocks cover up exactly this side. Next, the other side is $8 \mathrm{~cm}$ [point to the base of the triangle]. How many blocks are needed to cover up this side?

Interviewee: 8 .

Interviewer: Good. 8 blocks. A figure with a length of $8 \mathrm{~cm}$ and a width of $2 \mathrm{~cm}$ can be covered up completely by the blocks. What shape would it look like?

Interviewee: Rectangle.

Interviewer: Good! However, is this figure [point to the triangle] a rectangle?

Interviewee: No.

Interviewer: Good. What is its size [the triangle] compared with that of the rectangle?

Interviewee: Half.

Interviewer: Good. So, if here is a rectangle with a width of $2 \mathrm{~cm}$ and a length of $8 \mathrm{~cm}$, what is its area?

Interviewee: ... [Thinking but no response.]

Interviewer: Suppose the rectangle was completely covered up by the $1-\mathrm{cm}^{2}$ square units. The length of this side is $2 \mathrm{~cm}$ [pointing to the vertical side] and the length of the other side is $8 \mathrm{~cm}$ [pointing to the horizontal side]. How many blocks are needed to cover up this side [pointing to the horizontal side]?

Interviewee: 8.

Interviewer: Good. When this figure is covered up, what shape would it look like?

Interviewee: Rectangle.

Interviewer: Good. How many blocks are needed to cover up the rectangle?

Interviewee: 16.

Interviewer: Good. However, does the figure shown in the question look like a rectangle?

Interviewee: No.

Interviewer: It is not a rectangle. What is its size compared with that of the rectangle?

Interviewee: Half.

Interviewer: Good. The size of the triangle is half of the size of the rectangle. Then, how do you measure the area of the triangle?

Interviewee: Divide the measurement by 2 .

Interviewer: Good, divide the product of the length times the width by 2 . 